\title{
The role of tall buildings in sustainable cities
}

\author{
M. M. Ali \\ School of Architecture, University of Illinois at Urbana-Champaign, USA
}

\begin{abstract}
Tall buildings make up the urban fabric and cannot be viewed in isolation from the city. They also bring up ethical, social, and cultural issues, and they impact the local community - their social needs and what the neighborhoods can gain from creating a new tall building. As with the buildings themselves, the urban context in which tall buildings have evolved has changed dramatically since their Chicago origins, reflecting both social and technological developments. A tall building has been variously called a "city within a city," "a vertical city," and a "city in the sky." Thus it is apparent that a tall building is a microcosm of a large city. It is an integral part of the urban habitat having a close relationship with it. In a way it is a vertical progression of a horizontal city. The two are interactive and connected by the transportation, power grid, water supply, and waste production and disposal systems. The tall building can therefore play a vital role in defining livable and sustainable cities. Both cities and skyscrapers must use fewer natural resources; create less waste; and impact less on the natural world. Technology will continue to improve the physical systems of the skyscraper and the city; however, their future will be defined by human interests and values.
\end{abstract}

Keywords: sustainable development, tall building, city as ecosystem, skylines, megacities.

\section{Introduction}

It is projected that by 2030,5 billion people will live in urban areas throughout the world [1]. Whereas 30 per cent of the world population lived in urban areas in 1950, the proportion of urban dwellers climbed to 47 per cent in 2000 and is projected to rise to 60 per cent by 2030 . Energy shortage, global warming, urban sprawl, air pollution, overflowing landfills, water shortage, disease and global conflict will be the legacy of the twenty-first century unless we move quickly towards the notion and implementation of sustainability. Survival of the human 
race depends upon the survival of the cities - their built environment and the urban infrastructure. This will warrant vision, commitment, and action through the partnership and commitment of governments, policy makers, experts and the involvement of citizens. It will require the collaboration of urban planners, architects, engineers, politicians, academics, and community groups.

\section{The concept of sustainable development}

In 1983, the United Nations established the World Commission on Environment and Development in an attempt to resolve the conflicts arising out of the aspirations of both developed and developing worlds. In 1989 it published "Our Common Future" or the Brundtland Report [2], which launched the expression 'sustainable development' which was reinforced in 1992 at the Earth Summit in Rio. Sustainability was projected as an agenda to solve the global environmental problems and to facilitate the economic development of the underprivileged nations. The idea of protecting the environment thus morphed from the political to the economic agenda by 1992 .

The following four characteristics were derived from the Brundtland Report [3]:

- The elimination of poverty, especially in the Third World, is necessary not just on human grounds but as an environmental issue.

- The First World must reduce its consumption of resources and production of wastes.

- Global cooperation on environmental issues is an essential option.

- Change towards sustainability can only occur with community-based approaches that take local cultures seriously.

Ecological and environmental concerns had expanded beyond the issue of the consumption of non-renewable energy sources. The massive consumption of natural resources - both renewable and non-renewable - during the economic upturn of the 1980s had placed a severe strain on global supplies and caused irreparable damage to the atmosphere. The energy conservation movement of the 1970s merged with the economic development movement of the 1980s in an effort to avoid the problems caused by hastily planned developments of the early twentieth century without a clear vision of the future. As a result, environmental concerns were addressed by many disciplines in academia, business and the government - concerns that led to the new era of sustainability.

The most popular definition of sustainability was stated in the Brundtland Report [2]: "Development which meets the needs of the present generation without compromising the ability of future generations to meet their own needs."

\section{Sustainable cities}

On a macro-scale, a sustainable city means a livable city in which the past is preserved but it looks into the interest of those who are not born yet, that is, the posterity. In such a city the urban systems and the infrastructure are planned and designed for long-term requirements in mind. Perhaps a 100-year time frame is a good bench mark for which cities may be designed or renewed. It must be 
ensured that the city will survive over a long period of time maintaining its integrity, normal functioning, self-reliance and the health and welfare of its inhabitants. The city must also ensure quality of life for its residents while simultaneously ensuring its robustness and adaptive capacity. Livability, resiliency, and sustainability are three intertwined elements that together will define the quality of life of present and future generations inhabiting the city.

\subsection{The urban challenge}

The United Nations Human Settlement Program (UN-HABITAT) sponsors World Urban Forums (WUF) every two years to discuss the urban issues. One of the nine programs under UN-HABITAT is the Sustainable Cities Program (SCP). The WUF3 held in Vancouver in 2006 focused on urbanization as an allencompassing global phenomenon and attempted to recommend effective actions to achieve a sustainable process of global urban transformation by balancing social, economic, environmental, and political goals. Urban environmental problems consolidate a serious threat to the full materialization of the socioeconomic benefits that may be contributed by cities. Environmental deterioration results in enormous costs, resulting in inadequacies to tap local resources. The environmental planning and management (EPM) approach of the SCP addresses the urban challenge by promoting the sustainability of cities. Fig. 1 graphically shows the approach that has been adopted by numerous local and national governments and global non-government agencies (NGOs) and major companies [4].

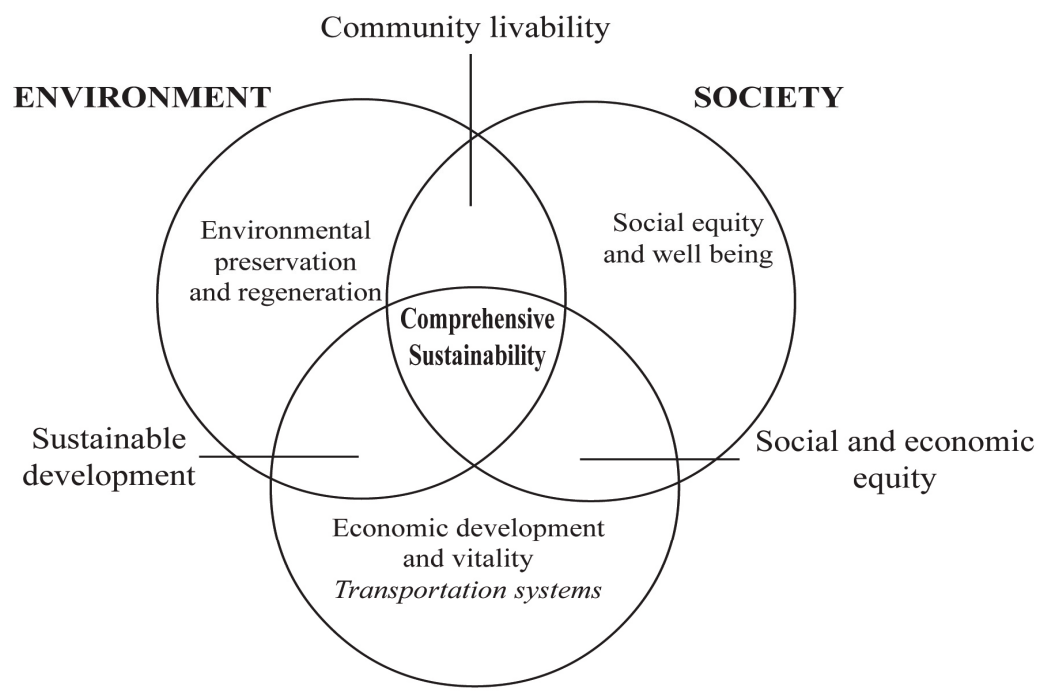

\section{ECONOMY}

Figure 1: Overlapping areas of economy, environment, and economy required for sustainability [4]. 


\section{The city as an ecosystem}

In order to deal with the concept of urban sustainability, the city needs to be viewed as an "ecosystem" which is complex and dynamic. As for an ecosystem, the city is an open system, having inputs of energy and materials; the main environmental challenges are related to sustaining the growth of these inputs and managing the outputs [3]. By viewing a city holistically as a "total system" and by analyzing the routes through which energy flows and materials move, it is possible to conceive of technologies and management systems which permit and facilitate the reintegration of natural processes, augmenting the efficiency of resource use, the recycling of wastes as valuable materials, and the conservation of energy.

\subsection{The city as an organism}

Metabolism is a biological term that views a living being's survival through the equation of resource inputs and waste outputs. The biological approach emphasizing growth and change, pioneered in architectural discourse by the Metabolism group in Japan, has been undertaken by some academics since 1965 , but has never been adopted or applied for urban planning [5, 6]. A city can be viewed as an organism. Fig. 2 shows a model known as the "External Metabolism Model" [3]. The physical and biological processes in this model are based on the natural laws of thermodynamics, which stipulate that anything

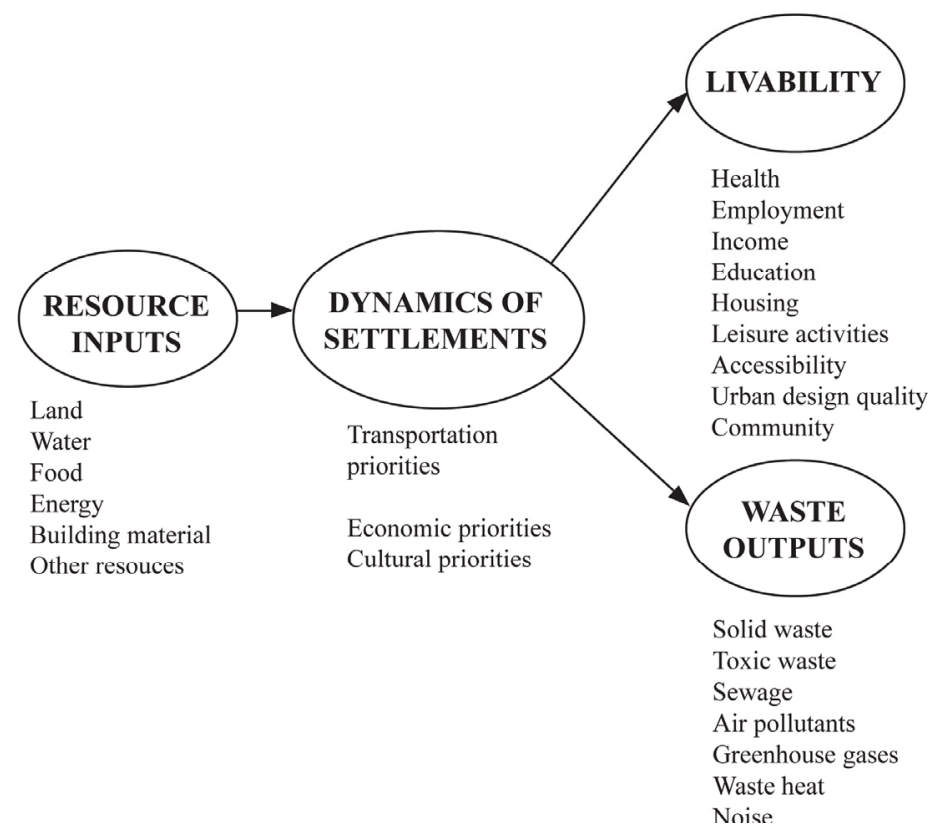

Figure 2: $\quad$ Extended metabolism model [3]. 
which enters into a biological system must pass through it and the amount of waste is dependent upon the amount of resources required to sustain the system. Thus a "balance sheet" of input and output can be produced. We can manage the wastes produced, but they require energy to turn them into anything useful and ultimately all materials will end up as waste without any room for recycling, thereby leading to entropy. The best way to reduce the impact is to reduce the resource input. A tall building, which is an analogous "vertical city", can be also viewed as a biological system and a similar 'Extended Metabolism Model' can be extended to it [7]. As cities grow and become complex, they begin to create diversity and efficiencies. They move toward a more efficient use of resources like a maturing ecosystem.

\section{From cityscape to skyscape}

The urban context in which tall buildings have evolved has changed dramatically since their Chicago origins, reflecting both social and technological developments [7]. In particular, the mass production of automobiles spurred a massive population shift from the cities to the suburbs in all parts of the developed world in the second half of the twentieth century. Concerned with the effect of these changes on the countryside, planning authorities in England and Sweden initiated ambitious programs for "exporting" the urban growth of their capitals to surrounding rings of the so-called New Towns of 60,000 and more people [8]. Based on the concept of Satellite Towns and Garden Cities, the lowdensity settlements were separated from the capital by "green belts" - areas of open land where new building was restricted - and were intended to offer new places of employment as well as decent, low-cost housing.

While the tenets of higher densities, mixed incomes, multi-use, and types of scales of buildings form the basis of most planning strategies, incorporation of high-rise towers is generally avoided or criticized as possible alternatives to more traditional low-scale buildings. Some reasons given for building tall are: human urge and ambition to build tall; important instrument for shaping and marking urban space; high land cost in urban cores; preservation of parks and other green spaces by saving land; high-rise in urban cores provide space for low-rise construction for those who cannot adjust to vertical living; reduction of urban sprawl and the growing network of transportation resulting in increased energy consumption; better views etc. [9]. The basic justification is agglomeration, and the sense of commercial "togetherness" for office buildings. Clustering also helps in reducing cost of urban services. Many cities in Europe and North America have developed strategies that involve consideration for "green roof" [10].

Perceptions of vertical architecture and its impact on densification are also changing. Improvements in the design of tall buildings and the way they connect with the urban sites in which they stand, have resulted in a new generation of buildings that are harmonious with their urban contexts, yet increase the density of the city. The landscaped public plazas of the Riverside Development of 1986 in Brisbane, Grosvenor Place of 1988 in Sydney and the QV1 Office Tower of 
1991 in Perth, all in Australia, are good exemplars of how tall buildings can contribute to the quality of urban life. Buildings such as Menara Mesiniaga in Kuala Lumpur, Malaysia and the Commerzbank in Frankfurt, Germany with their sky gardens and the Capita Centre in Sydney, Australia with its open ground-floor gardens, show how green spaces can be incorporated into tall buildings, thereby contributing to the sustainability of cities. There are other examples of sustainable tall buildings in major cities [7].

\section{Skylines as symbols in transition}

The best views of a city are seen when one is away from it. In this way, skylines become important and symbolic. They form a local emblem for the city besides being symbols of an industrialized and economically prosperous culture. Skylines are not typically fixed and finished, but reflective of continuing social change.

It is a well-recognized fact that a city will continue to grow whether or not it is desirable. Growth is not something that can be stopped, only contained and influenced. Despite the global and local effects, the cities will always thrive and continue to exist. The places they thrive will be the cities best prepared to deal with growth. Supertall buildings and megastructures are the likely solutions to the problems that megacities will face in the not-too-distant future.

\section{Planning for population growth}

Pollution, traffic gridlock, deteriorating infrastructure, water and energy shortage are universal problems in cities whether they be large or small in size. These issues only become multiplied in megacities with 10 million or more inhabitants. There is a trend in population growth in developing countries that is severely affecting the world population. The Population Division of the United Nations has predicted that the urban population will grow by $75 \%$ by the year 2050 . This means that not only is the world population growing but also that the percentage of people living in the city is increasing even faster.

Planning for the increases in population and ground coverage of growing cities has been hard to foresee in the past. Today it is apparent, however, how fast and at what magnitude a city can grow over a short period of time whether that city is prepared or not. By definition it is the government's responsibility to prepare cities for expansion. Only a government can make and enforce the laws necessary for a successful growth of a city.

\section{Integration of tall buildings and cities}

To understand the role of tall buildings in the urban fabric, the city must be viewed in three dimensions, not merely on a master plan in plan view, but also vertically where they encounter the interference effects of the atmosphere. It needs to physically integrate to the image of the city, to the city block, and to the adjacent structures. Most importantly, it must resolve how it relates to the 
street's edge, the pedestrian scale that it is around, and the existing land use. The combination of tall buildings and urban environment creates a special relationship because one helps define the other.

Whereas the integration of building systems inside the tall building takes place on a micro-scale, the same happening for the tall buildings in the urban context represents the macro-scale. The macro-scale environment is that of the entire cityscape, encompassed by the boundaries set by the city limits, of which a tall building is a small but significant part.

The city's land-use plan and its transportation plan must be interlinked so that changes can be properly anticipated and accommodated without deterioration of the city's transportation systems and other services $[7,11]$.

During the second half of the twentieth century, massive population shifts from the cities to the suburbs occurred in all parts of the developed world. In recent years, this trend of "urban dispersal" is returning to "densification" of urban areas through redevelopment programs, often invoking tall buildings of all kinds, whether commercial, residential, or mixed-use [8]. Improvements in the design of individual structures, not only as they appear above the ground but also in the way they connect with urban sites in which they stand, have also played a part in changing perceptions of vertical architecture. The tall building should be considered a "vertical urban design" and that "all the conventional considerations in the ground-plane of any typical urban design project need to be applied to the vertical plane of the skyscraper" [12].

\section{Megacities and urban strategies}

According to Beedle [13], if the tall buildings are "good", it means improved urban environment. If they are "bad", hardly anything can be done to improve the city. So when we say "good" and "bad", in connection with skyscrapers, we do not mean the structure or the architecture alone. We are, also, and may be most importantly, talking about their "planning and design" in a large context.

\subsection{Environmentally responsive approach}

There is the internal environment and the external environment for a tall building. Besides the normal concerns that apply to all buildings, this can cover such things as (a) vistas and views, (b) internal courtyards, (c) creation of a "sense of place", (d) and a consideration of life style of those who are not yet accustomed to city living.

The tall building is part of the urban system, a system whose quality it can create. This comprises the external environment. Thus, the planning and design must necessarily include not only structure and architecture, and the adjacent buildings and street space, but also the interface with people's interest at the street level (first floor shops and amenities), with the transportation system, with business and residential activity, with the cultural life of the city at its center, with the basic urban services of power, sanitation, water supply, and even with the "impact" of the skyscraper on the cityscape from outside the city walls [13]. 
Many architects, engineers, and planners believe that large and denselypacked urban buildings, if properly designed and constructed to positively respond to the environment, represent an inherently sustainable or green form of development. To achieve these goals, building professionals are increasingly resurrecting strategies that were routinely employed in smaller structures in the past, such as natural ventilation and shading devices to reduce heat gain, and adapting them to larger and more complex buildings. Meanwhile, they are exploiting new technologies, from solar power cells to sophisticated wind turbines, to create a new breed of large-scale buildings that are both comfortable and environmentally benign. These innovations in renewable and other technologies allow some tall buildings to generate their own energy. Future tall buildings with high performance, zero energy and carbon neutral attributes will definitely contribute to the ideal of sustainability of future cities.

\section{Tall buildings in sustainable cities}

A tall building has been variously called a "city within a city," a "vertical city" and a "city in the sky." Thus it is apparent that a tall building is a microcosm of a large city. The skyscraper is indeed a vertical progression of a horizontal city. As already noted they are interactive and connected by transportation, power grid, water supply and waste production and disposal systems. Similar to the city that has all these systems, a skyscraper has these systems contained within it. Both the city and tall building need to be sustainable for the same reasons.

\subsection{The city as an agglomeration}

Skyscrapers are the outgrowth of high land prices and mass density in large cities. Contrary to many common misconceptions, the larger cities worldwide with more than one million people have smaller metabolic flows per capita in terms of energy, water, land inputs and waste outputs than smaller cities [3]. The reduction of metabolic flows is due to the economics of scale and density, producing greater efficiency in technology, more access to markets for recycling, better public transport, and a generally more efficient use of land.

A tall building also has analogous agglomeration characteristics like a city. A taller building, if properly designed, can be more energy-efficient as well as has lower per capita metabolic flows compared to low-rise buildings. Clustering of tall buildings reduces the carbon footprint and contributes to environmental economy. Moreover, there is a need for re-urbanization of cities to improve their sustainability by increasing the number of (preferably sustainable) taller buildings, which may attract tenants due to their location advantage in the downtowns. Based on a study of the city of Sydney, Newman argues that this has been happening there rapidly as part of a bigger economic process linked to the globalization of the economy [3]. Thus the processes of rebuilding can have most of the elements of sustainability - less resources and waste and higher livability. A study by Arief [14] for the city of Jakarta with 12 million residents is instructive for developing countries. The city had developed a set of high-rise 
buildings as replacement housing for squatters. Using the Extended Metabolism model it was concluded that either similar or reduced levels of resource inputs and waste outputs in the high-rise resulted and land efficiency in the high-rise is considerably better as is the management of the wastes.

\subsection{Transportation}

It is generally agreed that an efficient transportation system plays a vital role in realizing a sustainable city. Urban density is inversely proportional to gasoline use per capita simply because it shortens the distances of all modes of traffic and encourages walking, bicycling or transit as alternatives to private automobile. This also reduces large-scale air pollution. There are also economic sustainability improvements when cities are able to reduce their reliance on cars. Road-based cities are much more wasteful of their wealth simply because the lower the density of the city the more the wastes of its wealth on transportation. Providing extended roads and facilitating cars encourage urban sprawl, widespread pollution and more energy consumption. It is also less efficient in terms of infrastructure and if a city is constantly sprawling instead of renewing and reurbanizing, then there is less capital available for investment in productive, innovative developments of the city. Therefore, sustainable transportation in the form of mass rapid transport (MRT) can contribute to sustainable development of the city supported by constructing more tall buildings at or near transportation hubs or nodes and containing sprawl; that is to say, by emphasizing the compactness of a city. The negative side of this is that such centralization will generate traffic congestion in the central business district (CBD) causing concentrated greenhouse gas production unless buildings are designed as carbon neutral. This suggests that fewer sustainable tall buildings rather than more lowrises buildings distributed across nodes in the metropolitan area close to transportation hubs will be beneficial not only for reducing greenhouse gas production but also for decreasing inequity in the access to employment and the range of cultural and recreational opportunities the city has to offer.

Although sustainability of major cities that include tall buildings encourages large but compact cities, we must not close our door to other options in which sustainability objectives can be reached without relying on highly concentrated and centralized services. The challenge is to find the right balance.

\section{Conclusions}

Tall buildings have a major role in defining major sustainable cities of the future. The urban challenge of creating livable cities needs to be vigorously pursued. Ensuring that communities work together within major cities should be a foremost policy for achieving sustainability. Tall buildings are unavoidable in such cities and must be considered as integral to the quest for sustainability of cities.

There are two possible directions which each of today's cities can take that will determine how successful they become in the future. In the past, the focus has been on what a utopian city of the future would be. This path seems 
fascinating when not contrasted with a prediction of what is horribly possible if the problems of cities were to be ignored. The representation of a deficient city of the future on the other hand is as wild as that of a utopian city. The reality is that increasing population and limited natural resources pose serious constraints on the development of future cities, and solutions for these problems must be incorporated in their long-tern planning and design. In order for low and zero energy and carbon neutral tall buildings to become a reality, a mandatory shift from fossil fuels to non-renewable energy is needed at a global scale, which in turn will contribute to the growth and development of sustainable cities.

\section{References}

[1] United Nations, Future world population growth to be concentrated in urban areas, United Nations Population Division Report, March 2001.

[2] WCED, Our Common Future, World Commission on Environment and Development, Oxford University Press: Oxford, UK, 1989.

[3] Newman, P., Sustainability and cities: the role of tall buildings in the new global agenda, Proceedings of the CTBUH Sixth World Congress, Melbourne, Australia, pp. 76-109, 2001.

[4] Newman, P. and Kenworthy, J. R., Sustainability and Cities: Overcoming Automobile Dependence, Island Press: Washington, DC, 1999.

[5] Wolman, A., The metabolism of a city, Scientific American, Vol. 213, No. 3, pp. 179-190, 1965.

[6] Boyden, S., Millar, S., Newcombe, K. and O'Neill, B., The Ecology of a City and its People, ANU Press: Canberra, Australia, 1981.

[7] Beedle, L.S., Ali, M. M., and Armstrong, P. J., The Skyscraper and the City: Design, Technology, and Innovation, the Edwin Mellen Press: Lewiston, NY, 2007.

[8] Abel, C., Sky High: Vertical Architecture, Royal Academy of Arts: London, UK, 2003.

[9] Beedle, L.S., High-rise habitat, HABITAT, Vol. 2, No. 1/2, Pergamon Press: Oxford, UK, pp.101-131, 1977.

[10] Doshi, H., Greening from above: roofs as environmental infrastructure resources, Environmental Advisory Forum, Kingston, Ontario, Canada, October 21, 2006.

[11] Ali, M. M. and Armstrong, P. J., (eds), Architecture of Tall Buildings, McGraw-Hill: New York, NY, 1995.

[12] Yeang, K., The Skyscraper Bioclimatically Considered: A Design Primer, Wiley-Academy Group Ltd.: London, UK, 1996.

[13] Beedle, L.S., Urban Life and Tall Buildings, Fritz Laboratories, Lehigh University: Bethlehem, PA, 1975.

[14] Arief, A., A Sustainability Assessment of Squatter Redevelopment in Jakarta, Thesis ISTP, Murdoch University, Perth, Australia, 1997. 